\title{
TRIBOLOGICAL TESTING OF POLYMERIC MATERIAL
}

\author{
Dana Kubátová, Martin Melichar \& Alejandro Pereira
}
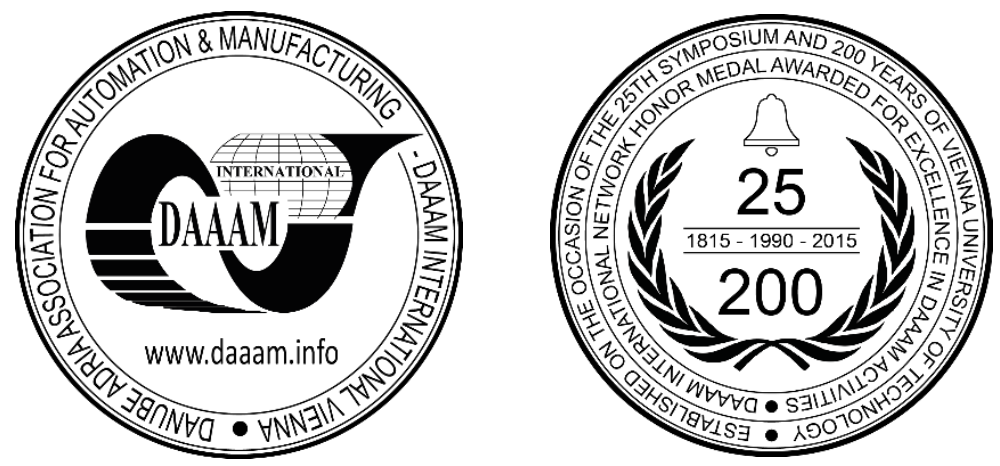

This Publication has to be referred as: Kubatova, D[ana]; Melichar, M[artin] \& Pereira, A[lejandro] (2016). Tribological Testing of Polymeric Material, Proceedings of the 27th DAAAM International Symposium, pp.0428-0434, B. Katalinic (Ed.), Published by DAAAM International, ISBN 978-3-902734-08-2, ISSN 1726-9679, Vienna, Austria DOI: $10.2507 / 27$ th.daaam.proceedings.063

\begin{abstract}
The article deals with testing the properties of specific materials - polymers. The basic idea was to confirm or refute the theory that materials with a higher modulus of elasticity will experimentally have lower wear. A precision tribometer at the experimental laboratories of the University of Vigo (where the international cooperation on the experiments took place) was used to test and find the origin of the wear. For the relevant documentation and independent verification, the map of wear was verified on a highly accurate profile/roughness measurement device at the metrology laboratories in the RTI at UWB in Pilsen.
\end{abstract}

Keywords: ABS polymers; PA6,6+15\% glass fibres; Tribotest Pin-on-Disk; Friction coefficient; Weight lost; Wear map

\section{Introduction}

In the technical, social and natural fields science there are many unresolved issues and problems that scientists are looking for the answers to, either in the form of answers at the theoretical level or in practical application. After a period of massive development of R\&D during the last century, when energy efficiency and environmental protection was not often considered, over the last few decades, and in the third millennium, there has come a sobering awareness of the need to save all kinds of energy. This is occurring against the background of expansion and development of many disciplines relating to the quality of human life, human needs and the desire to discover.

To fulfil these goals today machine and system builders should be equipped with fairly deep knowledge of many disciplines. This information enables them to solve problems in many areas. [1]

Situation in the field of durability and wear of machine parts exposed to friction and wear is completely different. In many cases the designers do not have necessary knowledge and technical documentation about this. The problem stems primarily from the complexity interaction of the materials on the functional surface machine components, the variability of the operating conditions, which are determined by the dominant factors that are friction and wear. Particularly when is contact between moving parts metal on metal or a metal of an alternative material, such as e.g.: polymer.

\section{Polymeric material}

Polymeric materials are basically divided according to their properties for elastomers, thermoplastics and thermosets. For this test were selected samples from polymeric materials in the field of thermoplastics. 
- AKRYLONITRILBUTADIENSTYREN next only ABS

- POLYAMID 6.6 with $15 \%$ GLASS FIBRE next only PA6.6+15\%

- POLYAMID 6.6 next PA 6.6

- POLYAMID 6.6 with 30\% GLASS FIEBRES

Note: bold materials were tested

Why polymeric materials? The answer is simple, because since the time they were discovered, the man is trying various uses. Replace them other materials, which have either limited or a polymer with its specific characteristics surpass. Properties that polymeric materials over conventional materials are numerous. Among the most interesting, which make the polymers used are:

- Lightweight

- Electrical insulation properties

- Low thermal conductivity

- Corrosion Resistance

- Resistance to certain chemicals

- Flexibility / elasticity

- High fatigue resistance

- Resistance to aging

\section{Sample}

\subsection{Preparation sample}

For preparation samples was choosen method of injection moulding. Injection was performed on machine Engel Victory 28 that is in industrial laboratories of the University of Vigo.

The samples are in the form of a disc that have diameter $\varnothing 60 \mathrm{~mm}$ and a height of $3 \mathrm{~mm}$. Sample size was chosen with regard to the area to carry out all the tests, such as the repeated test tribometer, roughness measurements and other tests.

Parameters for injection were set according to the parameters provided by the manufacturer of the machine. The parameters used for injection are seeing in Table 1 and 2. As a variable parameter was chosen injection pressure in Table 2 marked yellow. These conditions were the same for both materials tested.

Furthermore, the material PA6.6 + 15\% GF was dryed before injecting material. Drying was carried out at $80^{\circ} \mathrm{C}$ for 10 hours.

\begin{tabular}{|c|c|c|c|c|c|}
\hline $\begin{array}{c}\text { Set max. Temperature } \\
\text { in the cylinders } /{ }^{\circ} \mathbf{C} /\end{array}$ & 265 & 255 & 240 & 220 & 40 \\
\hline $\begin{array}{c}\text { The actual temperature } \\
\text { in the cylinder } /{ }^{\circ} \mathbf{C} /\end{array}$ & 249,7 & 249,5 & 239,7 & 220 & 45,7 \\
\hline
\end{tabular}

Table 1. Temperature during injection

\begin{tabular}{|c|c|c|}
\hline Injection volume & $17 \mathrm{~cm} 3$ & $17 \mathrm{~cm} 3$ \\
\hline Max. pressure & $160 \mathrm{bar}$ & $160 \mathrm{bar}$ \\
\hline Piston diameter & $30 \mathrm{~mm}$ & $30 \mathrm{~mm}$ \\
\hline Time injection & $2 \mathrm{~s}$ & $2 \mathrm{~s}$ \\
\hline Cooling time in the form of & $20 \mathrm{~s}$ & $20 \mathrm{~s}$ \\
\hline Injection pressure & $100 \mathrm{bar}$ & $150 \mathrm{bar}$ \\
\hline Volume of the mould & $11 \mathrm{~cm} 3$ & $11 \mathrm{~m} 3$ \\
\hline
\end{tabular}

Table 2. Injection parameters

\subsection{Testing of sample}

Own tests selected plastic materials were conducted in cooperation of Metrology lab of University of West Bohemia in Pilsen and Laboratories University of Vigo.

This article partly describes preliminary tests. However, in this article we have already come into field of repeated tests. Because it was funded interesting information during the design of maps wear. 


\subsection{Tribological tests}

The variability of this test allows exploring the different possibilities of test materials. Tribotest setting options are almost limitless.

The task of tribology is description of materials behaviour in a relative motion. Tribology tested two or more materials in contact, or interaction of the material with the environment there is a loss of material from the surface, a process known as wear. The conditions used in the tests are shown in Table 3.

\begin{tabular}{|c|c|c|c|c|c|}
\hline Material & $\begin{array}{l}\text { Speed test } \\
\text { /rpm/ }\end{array}$ & $\begin{array}{l}\text { Radiu test } \\
/ \mathbf{m m} /\end{array}$ & $\begin{array}{c}\text { Load } \\
/ \mathrm{N} /\end{array}$ & $\begin{array}{l}\text { Time test } \\
/ \mathbf{m} /\end{array}$ & $\begin{array}{c}\text { Radius test } \\
\text { bodies } \\
/ \mathrm{mm} /\end{array}$ \\
\hline ABS-1-a & \multirow{3}{*}{200} & \multirow{6}{*}{9} & \multirow{3}{*}{20} & \multirow{6}{*}{200} & \multirow{6}{*}{4} \\
\hline ABS-1-b & & & & & \\
\hline ABS-2-a & & & & & \\
\hline ABS-2-b & \multirow{3}{*}{300} & & \multirow{3}{*}{30} & & \\
\hline PA-1-a & & & & & \\
\hline PA-2-a & & & & & \\
\hline
\end{tabular}

\section{Friction coefficient}

Table 3. Testing parameters

\subsection{ABS material}

This parameter is the most important value for this test. On the basis of information about the value of the friction coefficient, one is able to predict how the material will behave under load. Thus, both will be wearing, how will heat up or how it will deform...

The parameter is measured during continuous tribological testing and then this value continues to operate. This test measured the coefficient of friction for long term testing since the objective was to determine the mean coefficient of friction.

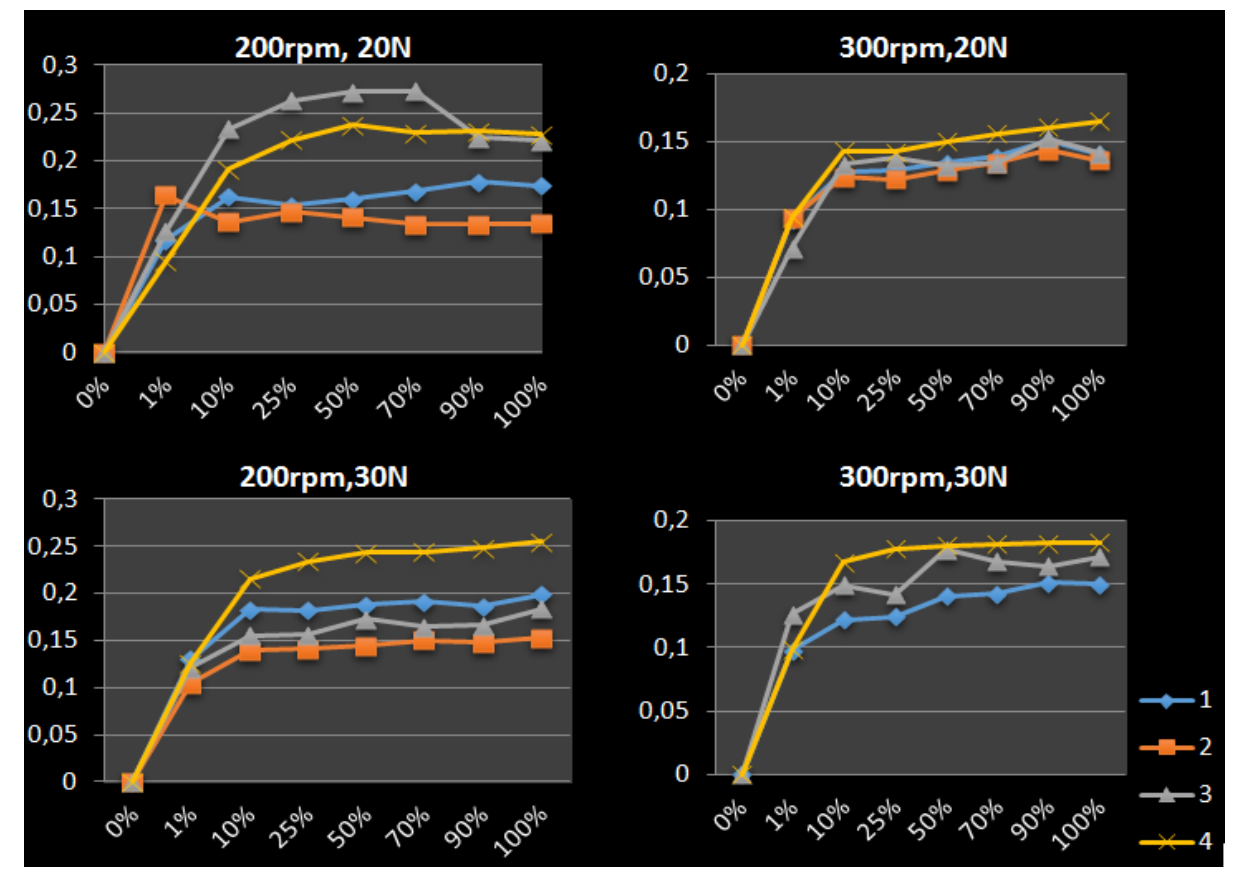

Fig. 1 Friction coefficient during testing for ABS material - according to the test parameters

Label groups:

- 1-150 bar and roughness poor

- 2-100 bar and roughness poor

- 3-100 bar and roughness good

- 4-150 bar and a roughness good 
The upward trend of the coefficient of friction is due to the fact that they still rises contact area when pike test specimen and the test sample.

In Fig. 1, graph 200rpm and 20N in Category 3 (gray line) shows a decreasing tendency from the value of $70 \%$ and is probably due to a problem in the structure of the sample.

Furthermore, this test confirmed that the friction coefficient depends on the value of surface roughness, as shown Fig. 1 in the following figures and example. At $200 \mathrm{rpm}$ and a load of $30 \mathrm{~N}$ it has the best surface roughness of the sample group which has poor roughness.

For better orientation, the effect of the load value, and scanning speed (time) is shown in the following Fig. 2 and $3 .$.

It is easy to see how changes the value of the coefficient of friction changes for each load and speed testing. It is seen that the coefficient decreases with increasing load and speed combination testing.

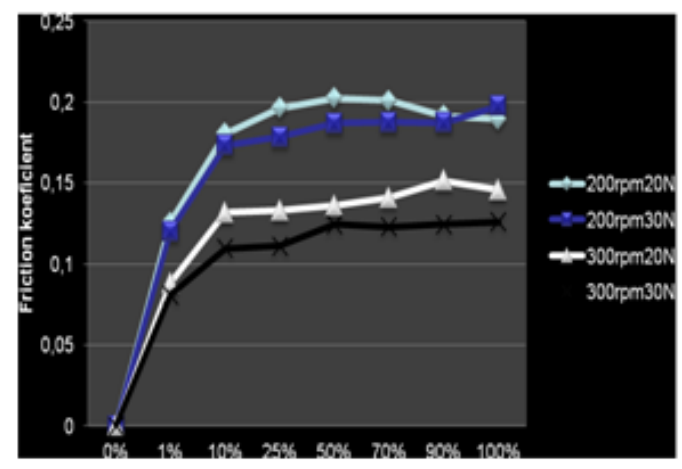

Fig. 2 Friction coefficient - ABS material summarization

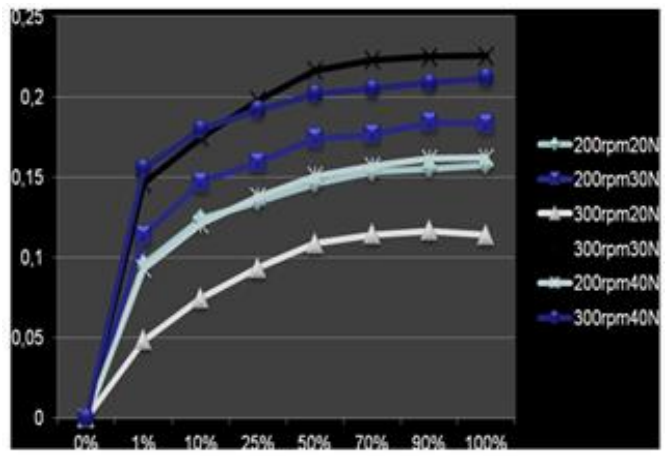

Fig. 3 Friction coefficient - ABS material summarization

\subsection{Polyamide material}

Even for this material, comparisons were made between the loads for the groups as in the previous tests. However, for these comparisons nothing unusual was found, therefore only the resulting comparison is given.

This comparison is interesting in that the greatest friction coefficient was achieved at maximum load. This can be anything from previous tests to explain why it is necessary to carry out further tests with those conditions and that both the load and speed of rotation but also the same moisture conditions. Moisture is needed in this case the guard due to the fact that PA6.6 + 15\% GF is a highly hygroscopic material.

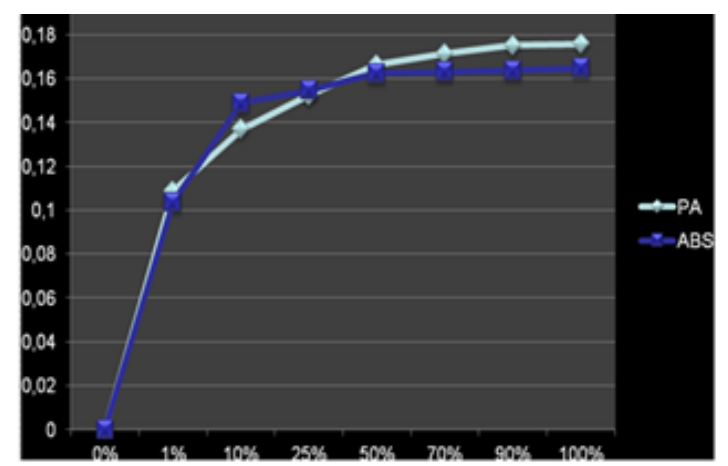

Fig. 4 Friction coefficient - comparison ABS and PA6,6+15\% GF 


\section{Change of weight}

The changing weight of the sample describes how much the research sample wears under the influence of higher pressure and cyclic effect (rotary) wear.

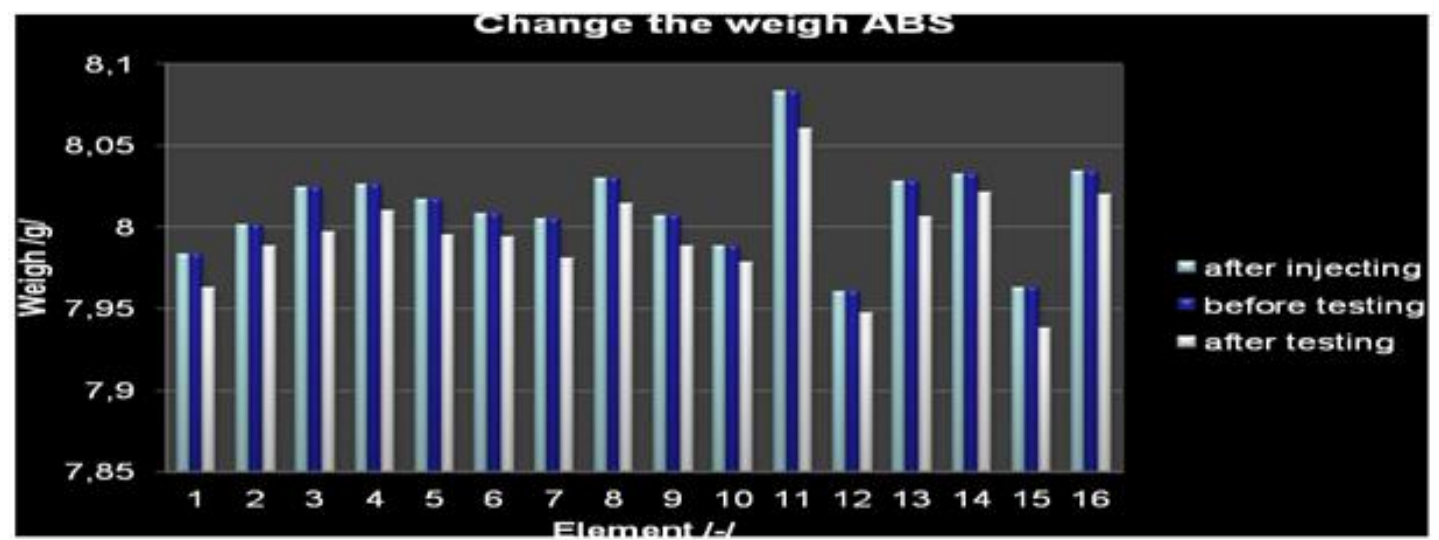

Fig. 5 Differences between weights for ABS material

Here, in the graph for PA6.6 + 15\% GF it is important to note that we changed the mass immediately after injection of the sample and before the test. This is due to the very high hygroscopicity material.

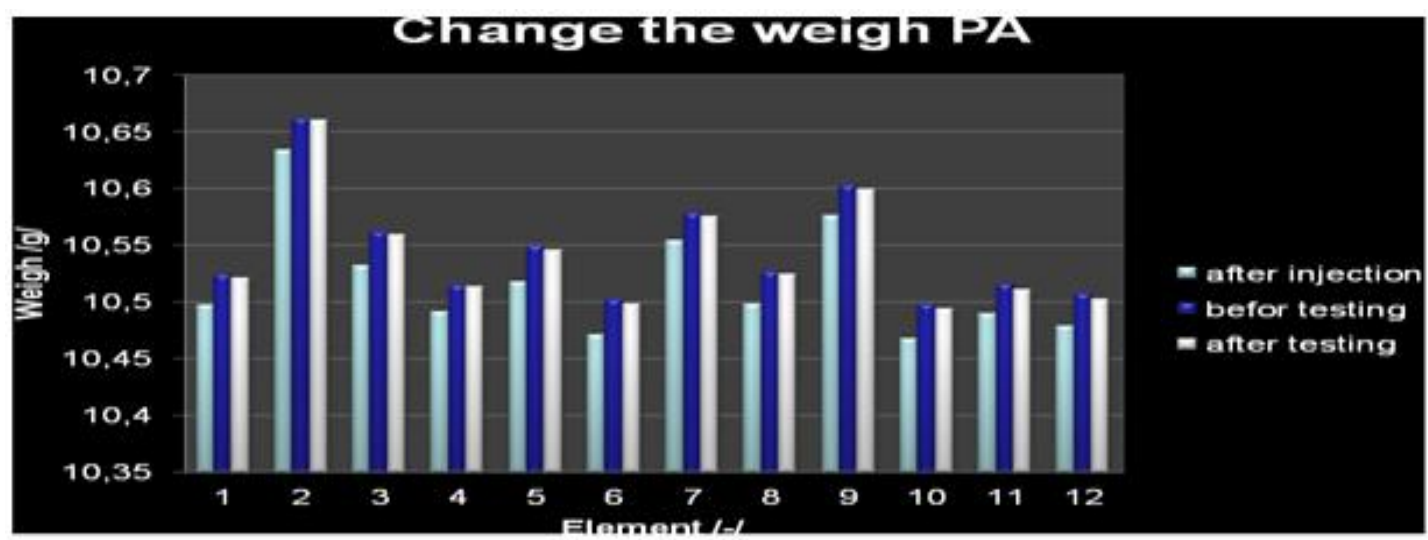

Fig. 6 Differences between weights for PA material

From Chart 3 it is already possible to say how the material will behave during further testing and what results can be expected from additional tests, and that material PA $6.6+15 \% \mathrm{GF}$ will better withstand potential stresses than ABS. In numbers, this is expressed by ABS during the test, lost $0.017 \mathrm{ga}$ PA $6.6+15 \% \mathrm{GF}$ lost $0.003 \mathrm{~g}$.

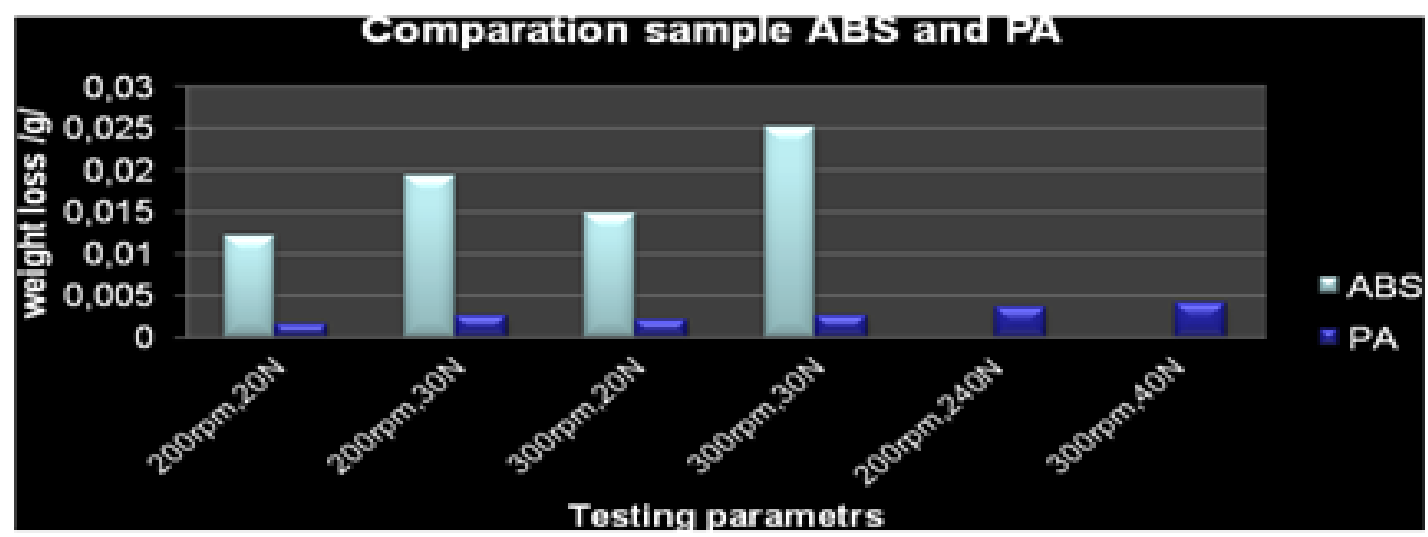

Fig. 7 Comparison ABS and PA material - weights lost 


\section{Wear map}

Wear maps describes how material will behave in the area of tested conditions. Maps are used to get quickly information about the material. Maps are use not only for getting behaviour but the maps are used for comparing two or more of the tested materials and on how they are against each other position of their mechanical properties. However, all this can be expected only if the tests are carried out under the same test conditions - the same testing body, our case was used steel ball diametre $4 \mathrm{~mm}$ and test conditions see Table 3 .

For construct a wear maps is necessary to know the width, depth and average diameter traces left at sample after the test tribometer.

To determine the actual width tracks and medium diameter traces were used a microscope connected to a PC in the laboratories of the University of Vigo. Images from this measurement can be seen in Fig. 8. The microscope was set lens 10x zoom 1x.
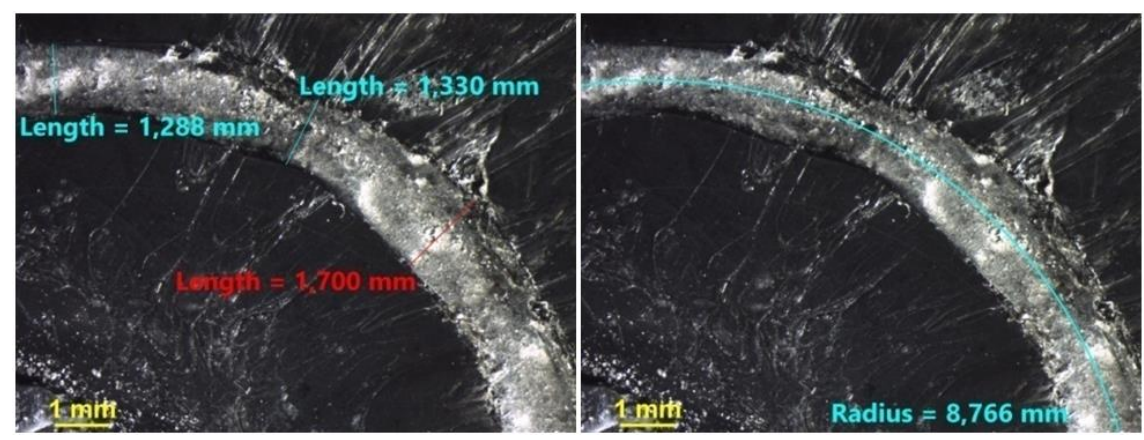

Fig. 8 Measuring stops after testing - width and radius

As an additional parameter is the depth of left traces. This was measured in Laboratories University of West Bohemia device to Etamic Hommel T8000. Device enables to measure both the profile and roughness of components. There was used the profile measurement. The output from the measuring is seeing on Fig. 9. The red box in Fig. 9 is marked path area after tribotest.

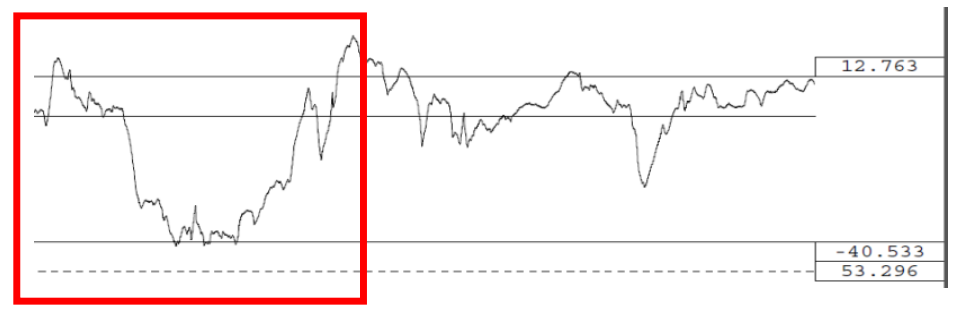

Fig. 9 Measuring stops after testing - deep

After obtaining all the parameters necessary for calculating the wear map has been calculated to obtain data for constructing and plotted into a graph that can be seen in Fig. 10.

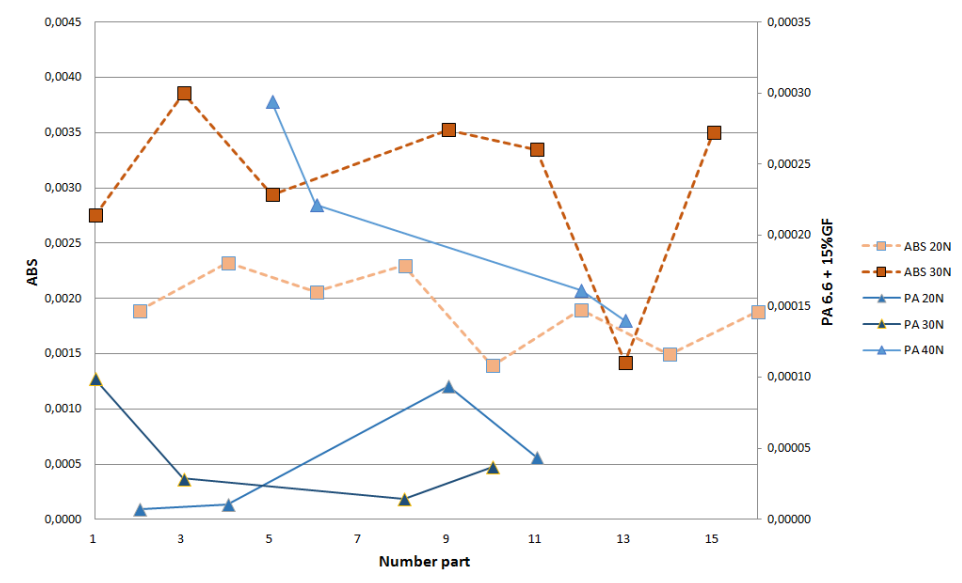

Fig. 10 Wear map for two materials 
Usually wear maps are constructed only of individual points. However, when is given two or more materials into one wear maps is difficult to orientation in this map. Therefore in this case is map completed by connecting lines, which enable easier orientation in the chart.

\section{Conclusion}

ABS and PA are polymers and are thermoplastics. Therefore, they should have roughly the same properties and characteristics as some specific parameters for these materials.

Even in terms of comfort for the test were as arm Vibration noise or better based material PA6.6 + 15\% GF.

In the article non-traditional is map designed for wear two materials together. Here the article being wear value related to the ratio of modulus of elasticity. The modulus of elasticity was chosen because it clearly defines the internal structure of the material. Assumption was that for the same test parameters (conditions tribotestu) should result in less wear on the material with higher modulus of elasticity. This hypothesis was confirmed, but not the value of the wear. The wear values could according modulus should differ by about $70 \%$. While the wear values differ by more than $90 \%$.

If the resultant product is used as an exposed part, according to the test the clear choice is ABS. This is covered by acquired better visual structures and surface roughness, and after averaging all values amino slightly smaller friction coefficient than PA66 + $15 \%$ GF.

However, when used as a loaded component, this material is very difficult to use. Large wear loss of material occurs when loading, which is adhered in the form of fine dust on all around visibility

\section{Anknowligement}

The present contribution has been prepared under project LO1502 'Development of the Regional Technological Institute' under the auspices of the National Sustainability Programme I of the Ministry of Education of the Czech Republic aimed to support research, experimental development and innovation.

\section{References}

[1] M. Renouf, F. Massi, N. Fillot, A. Saulot, Numerical tribology of a dry contact, Tribology International, Volume 44, Issues 7-8, July 2011, Pages 834-844, ISSN 0301-679X, http://dx.doi.org/10.1016/j.triboint.2011.02.008

[2] T. Mathia, P. Pawlus y M. Wieczorowski, «Recent trends in surface metrology,» Wear, p. 494-508, 2011

[3] D. Kubátová, M. Melichar, A. Pereira, Comparative Study of Tribological Behaviour of Polyamide and Abs Polymers After Processing by Injection

[4] J. Sudeepan, K. Kumar, T.K. Barman, P. Sahoo, Study of Friction and Wear of ABS/Zno Polymer Composite Using Taguchi Technique, Procedia Materials Science, Volume 6, 2014, Pages 391-400, ISSN 2211-8128, http://dx.doi.org/10.1016/j.mspro.2014.07.050

[5] ASM handbook. 10th editon. Materials Park, Ohio: ASM International, 2016. ISBN 1615038272 